\title{
Outcome of Endoscopic Variceal Band Ligation
}

\author{
Barun Shrestha, ' Sudhamshu KC, ${ }^{2}$ Sitaram Chaudhary, ${ }^{1}$ Bhupendra Kumar Basnet, ${ }^{1}$ Amrendra Kumar Mandal, ${ }^{1}$ \\ Nandu Silwal Poudyal' \\ 'Gastroenterology Unit, Department of Medicine, NAMS, Bir Hospital, Kathmandu, Nepal, ${ }^{2}$ Hepatology Unit, Department of \\ Medicine, NAMS, Bir Hospital, Kathmandu, Nepal.
}

\section{ABSTRACT}

Introduction: Bleeding from esophageal varices in cirrhosis is an emergent condition with high mortality. One of the preferred modality of treating esophageal varices is EVL. We aimed to find out the outcome of EVL in controlling acute esophageal variceal bleeding, prophylactic banding to prevent future bleeding and the number of sessions required for complete eradication of varices.

Methods: This descriptive observational study was carried out in Gastroenterology and Hepatology unit of Bir Hospital, NAMS from June 2016 to May 2017. Consecutive cases who presented in emergency room with acute variceal bleeding due to liver cirrhosis and cases of liver cirrhosis with large varices and red color signs on endoscopic examination were enrolled. They underwent EVL and subsequent re-endoscope at one month interval till the eradication of varices was achieved.

Results: Among 83 patients, 15 (18.1\%) were of Child Pugh class A, 29 (34.9\%) B and 39 (47\%) were of C. In $20(24.1 \%)$ cases varices could be eradicated in one session of EVL while 57 (68.7\%) required two sessions and in $6(7.2 \%)$ cases it took three sessions. Total average EVL session required for obliteration of esophageal varices was $1.84 \pm 0.53$. There was only one $(1.2 \%)$ of early re-bleeding post EVL.

Conclusions: EVL is an effective modality of treatment in controlling acute esophageal variceal bleeding, in preventing future variceal bleeding as well as in eradicating esophageal varices with very few complications.

Keywords: acute variceal bleeding; cirrhosis; endoscopic variceal ligation; large varices; red color sign.

\section{INTRODUCTION}

Bleeding from varices in liver cirrhosis (LC) and portal hypertension is the leading cause of death. ${ }^{1}$ It is an emergent condition with high mortality. ${ }^{2-4}$ The prevalence of esophageal varices in LC is around $80 \%$ $90 \% 5,6$ and variceal hemorrhage occurs at a rate of $10 \%-30 \%$ yearly. ${ }^{7}$ Two studies from Nepal have shown esophageal varices as the cause of upper Gl bleeding in $47.5 \%^{8}$ and $15.6 \%{ }^{9}$ cases respectively.

Despite early management of variceal hemorrhage, the mortality remains $20 \%-35 \% . .^{10-12}$ The 6 -week mortality with each episode of variceal hemorrhage is $15-20 \%$, ranging from $0 \%$ among Child Pugh class $A$ to $30 \%$ among Child class C disease..$^{13-16}$ In recent years, application of esophageal variceal ligation (EVL) has reduced the mortality rate. ${ }^{16}$ For esophageal varices without associated gastric varices, EVL had shown good outcome. ${ }^{17}$

This study was done to see the outcome of EVL in controlling acute esophageal variceal bleeding, outcome of prophylactic banding of large varices with red color signs and the number of sessions required for complete eradication of varices.

Correspondence: Dr. Barun Shrestha, Gastroenterology Unit, Department of Medicine, NAMS, Bir Hospital, Kathmandu, Nepal. Email: barunshh@yahoo.com, Phone: +977-9855064500. 


\section{METHODS}

This descriptive observational study was carried out in Gastroenterology unit and Hepatology unit of Bir Hospital, NAMS during the period of one year starting from June 2016 to May 2017. Ethical approval was taken from Institutional Review Board (IRB), NAMS and written informed consent was taken from each patient. Consecutive cases of acute variceal bleeding who presented in emergency room of Bir hospital with acute variceal bleeding due to cirrhosis and admitted in the Gastroenterology and Hepatology Unit, cases of varices with history of bleeding in recent past and patients with large varices with red color signs found during evaluation of cirrhotic patient were enrolled in this study. After admission of all the cases of acute variceal bleeding, they were resuscitated, evaluated with history, physical examination and baseline investigations like complete blood count, renal function test, liver function test, random blood glucose, HBsAg, Anti HCV and ultrasonography of the abdomen were done. And the same investigations were done for the admitted cases of another decompensated LC. All patients underwent endoscopy after informed written consent, to confirm the esophageal varices and bleeding site. Cases excluded were I) Small esophageal varices II) Esophageal varices associated with fundal varix III) Varices secondary to non-cirrhotic portal hypertension and IV) Patients refusing for consent.

In all included patients, EVL was done with a 6 band ligator with $9 \mathrm{~mm}$ endoscope. The procedure was done by expert endoscopists in the respective units. At one session, up to 6 bands were deployed spirally below above from the esophago-cardiac junction (ECJ) in elective cases. Whereas in case of acute bleeding, after resuscitation, endoscopic band ligation was done starting from the point of recent bleeding and then spirally below above from the ECJ. All the patients were observed for the next 24-48 hours in hospital for any immediate complications, and re-endoscopic evaluation was done in one month follow up. During follow up for re-endoscope hemoglobin, platelets and prothrombin time (PT) with INR were done and recorded in each case. In needful cases, subsequent EVL was done again monthly by the same method till complete obliteration (non bandable due to inability to suck the varix into the band cylinder during EVL) was achieved. All the immediate and late outcomes of each procedure were recorded in Microsoft Excel and analyzed with SPSS 17 software.

\section{RESULTS}

During the study period, 83 patients of liver cirrhosis were treated with EVL for acute variceal bleeding and large varices with red color signs. Among 83 patients, there was male preponderance, 67 (80.7\%) male Vs. $16(19.3 \%)$ female. The mean age of the patients was $49.48 \pm 12.2$ years. Most number of patients were from the Gurung/Magar ethnicity 22 (26.5\%), followed by Kshetriya20 (25.3\%) and Newar ethnicity 18 (22.8\%). The most common cause for LC was observed to be alcohol with history of consumption of alcohol in average of $40.3 \pm 31.76 \mathrm{gm} /$ day for average duration of $13.04 \pm 6.31$ years. One $(1.2 \%)$ case each of chronic $\mathrm{HBV}$ and Chronic HCV was also observed among the selected patients.

The baseline characteristics of patients enrolled at the first presentation had mean systolic blood pressure of $109.18 \pm 14.72$ and diastolic blood pressure of 71.53 $\pm 10.12 \mathrm{~mm} \mathrm{Hg}$ (Table 1).

\begin{tabular}{|c|c|}
\hline Variable & Value (mean $\pm S D)$ \\
\hline $\begin{array}{l}\text { Systolic blood pressure } \\
(\mathrm{mmHg})\end{array}$ & $109.18 \pm 14.72$ \\
\hline $\begin{array}{l}\text { Diastolic blood pressure } \\
(\mathrm{mmHg})\end{array}$ & $71.53 \pm 10.12$ \\
\hline Hemoglobin (gm/dL) & $10.03 \pm 2.07$ \\
\hline White blood count $\left(/ \mathrm{mm}^{3}\right)$ & $8324.7 \pm 6417.53$ \\
\hline Platelets $\left(/ \mathrm{mm}^{3}\right)$ & $130630 \pm 77651.93$ \\
\hline Bilirubin(mg/dL) & $4.1 \pm 4.68$ \\
\hline $\mathrm{ALT}(\mathrm{IU} / \mathrm{mL})$ & $42.92 \pm 27.38$ \\
\hline AST (IU/mL) & $87.33 \pm 68.64$ \\
\hline Alkaline Phosphatase (IU/mL) & $112.31 \pm 85.14$ \\
\hline Albumin (gm/dL) & $2.93 \pm 0.59$ \\
\hline INR & $1.51 \pm 0.36$ \\
\hline Spleen size (cm) & $13 \pm 1.73$ \\
\hline
\end{tabular}

$\mathrm{ALT}=$ Alanine $\quad$ aminotransferase,$\quad \mathrm{AST}=$ Aspartate Aminotransferase, INR = International Normalized Ratio.

Severity of the disease was assessed by Child Pugh Status. Nearly half of the patients were in Child C group and around one third were in Child B group (Table 2). This is well understood as more severe the disease, there will be more portal hypertension and thus esophageal varices.

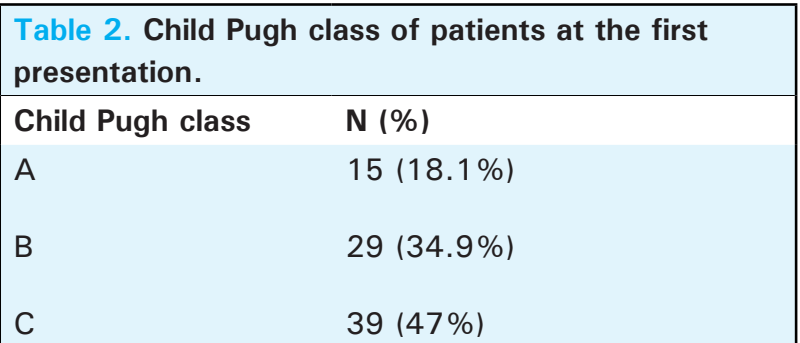


The presenting symptoms of abdominal distension and malena were the most common 59 (71.1\%) each followed by hematemesis $46(55.5 \%)$, jaundice $42(50.6 \%)$ and early satiety in $5(6 \%)$ at the first presentation. On examination of all the enrolled patients at the time of first presentation, spider angioma was found in $70(84.3 \%)$, loss of axillary hair in $52(62.7 \%)$, gynaecomastia in $49(59 \%)$, parotid swelling in 16 $(19.3 \%)$, alopecia in $11(13.3 \%)$, and asterixis in 6 $(7.2 \%)$. In the first follow up of all 83 patients' average hemoglobin was $10.3 \pm 1.9 \mathrm{gm} / \mathrm{dl}$, average platelet was $101000 \pm 45030.4 / \mathrm{mm}^{3}$ and INR of $1.45 \pm 0.37$, which were done before the endoscopic examination, and 63 patients underwent EVL. Similarly, at the third session of endoscopic evaluation and treatment among 63 patients, average hemoglobin was $10.5 \pm 1.02$ $\mathrm{gm} / \mathrm{dL}$, platelet $104500 \pm 42098.7 / \mathrm{mm}^{3}$ and INR was $1.65 \pm 0.49$, and only 6 patients underwent third session of EVL. Finally those 6 patients who underwent the final endoscopic evaluation had average hemoglobin of $10.8 \pm 1.7 \mathrm{gm} / \mathrm{dL}$, platelets of $99010 \pm 20012.9 / \mathrm{mm}^{3}$ and INR of $1.5 \pm 0.31$. Most variceal eradication was achieved after second session of EVL in 57 (68.2\%) (Table 3).

\begin{tabular}{|l|l|}
\hline \multicolumn{2}{|l|}{$\begin{array}{l}\text { Table } 3 . \text { Number of patients achieving variceal } \\
\text { obliteration in different sessions. }\end{array}$} \\
\hline Number of sessions & $\mathbf{N}(\%)$ \\
1 & $20(24.1 \%)$ \\
2 & $57(68.7 \%)$ \\
3 & $6(7.2 \%)$ \\
\hline
\end{tabular}

In 20 cases $(24.1 \%)$ varices could be eradicated in one session of EVL whereas in 57 (68.7\%) cases it could be done in two sessions and in $6(7.2 \%)$ cases it took three sessions. Average columns of varices in our study population were $3.80 \pm 0.56$. For same, the average number of bands deployed was $5.19 \pm 1.14$ in first sessions. In second session 63 (75.9\%) cases underwent EVL and average columns of varices were $2.41 \pm 0.90$, with average bands deployed were $2.89 \pm 1.83$. Only $6(7.2 \%)$ cases required third sessions of EVL and average of $2.5 \pm 0.54$ columns of varices were seen during re-endoscope. The average bands deployed in those cases were $3.3 \pm 0.81$. Average EVL session required for obliteration of esophageal varices in our study population was $1.84 \pm 0.53$.

At the time of first EVL, 66 (77.9\%) cases had mild portal hypertensive gastropathy (PHG), 6 (7.2\%) cases had severe and $11(13.2 \%)$ had no PHG. There was no change in PHG grade in follow up of the respective cases during re-endoscopy. None of the cases in follow up endoscopy was found to develop fundal varices. Regarding complications of the banding procedure, after the first EVL, 38 (45.8\%) complained of mild chest discomfort, 7 (8.4\%) had mild dysphagia and one each fever and bleeding. This one case $(1.7 \%)$ of bleeding occurred in day seven after EVL and patient presented to ER and was managed conservatively. No major complication was observed after second and third session of endoscopic band ligation except for 25 $(43.8 \%)$ of mild chest pain in second session and two cases $(33.3 \%)$ of chest pain in the third session.

\section{DISCUSSION}

Management of variceal bleeding comprises pharmacologic, endoscopic treatment or combination of the two. Endoscopic sclerotherapy and EVL are currently practiced endoscopic modalities for the treatment as well as prophylaxis of variceal bleeding. EVL is the gold standard for the treatment of acute bleeding of esophageal varices. Furthermore, it is also effective in secondary prophylaxis and in primary prophylaxis for patients' who are not suitable candidates for beta blocking agents.

EVL has significantly reduced the frequency of variceal bleeding, mortality and complications as the first line therapy in esophageal variceal bleeding. ${ }^{18,19}$ However, this treatment has a high recurrence rate, also needs advanced technique and incurs high cost. ${ }^{20,21}$ Endoscopic variceal band ligation is mostly performed in the in-patient setting and is effective inprimary and secondary prophylaxis of bleeding esophageal varices in patients with cirrhosis. ${ }^{18}$ Our study was a single centered descriptive observational study in which EVL therapy after pre-endoscopic preparation of the patients and confirmation of esophageal varices was done to see the required numbers of sessions to obliterate the esophageal varices in LC patients. We achieved variceal obliteration in $20(24.1 \%)$ cases after the first session of EVL, in 57 (68.7\%) after the second session and $6(7.2 \%)$ after the third session of EVL. This result is different from a Pakistani study ${ }^{22}$ where variceal obliteration was achieved after the first, second and third session of EVL in $9.73 \%, 22.12 \%$ and $29.2 \%$ cases respectively. Moreover, $6.19 \%$ of cases underwent seven sessions of EVL to achieve the same. Contrary to this study, most number of variceal obliteration was achieved after the second session of EVL in our study. Another study showed variceal obliteration after 3-4 sessions of EVL. ${ }^{23}$

In our study, there was $45.8 \%$ of mild chest discomfort, $8.4 \%$ of dysphagia and $1.2 \%$ of post $E V L$ bleeding after the first session of EVL, all were managed conservatively and no long term undesired outcome like esophageal stricture, increase in fundal varices or increase in PHG were observed. Had we followed up these cases for longer time we would have 
observed increase in PHG and fundal varices as shown by Abbasi et al. ${ }^{23}$ No significant fall in hemoglobin was observed during the study period, indicating that EVL was effective in preventing variceal bleeding. Since we followed up the cases only till 3-4 sessions of endoscopy we could not know the natural course of esophageal varices after obliteration, also we could not know the progression of fundal varices and progression of PHG. Since our aim was to find out the outcome of EVL and number of sessions required for eradication of the esophageal varices, analysis of other complications of decompensated liver cirrhosis was beyond the scope of this study. Short follow up and small sample size was the limitations of our study.

\section{CONCLUSIONS}

EVL is an effective therapy for acute variceal bleeding and for primary and secondary prophylaxis of esophageal variceal bleeding. It has few adverse outcomes, and it is also effective for eradication of esophageal varices. Variceal obliteration can be achieved in less than three sessions of EVL. Thus, EVL can be used to control and prevent esophageal variceal bleeding as well as to eradicate the esophageal varices in patients of LC.

\section{Conflict of Interest: None.}

\section{REFERENCES}

1. Sorbi D, Gostout CJ, Peura D, Johnson D, Lanza F, Foutch PG, et al. An assessment of the management of acute bleeding varices: Amulticenter prospective member-based study. Am J Gastroenterol. 2003 Nov;98(11):2424-34. [PubMed | DOI]

2. Lay CS, Tsai YT, Lee FY, Lai YL, Yu CJ, Chen CB, et al. Endoscopic variceal ligation versus propranolol in prophylaxis of first variceal bleeding in patients with cirrhosis. J GastroenterolHepatol. 2006 Feb;21(2):413-9. [PubMed $|\underline{\text { DOI }}| \underline{\text { Full Text }]}$

3. Wright AS, Rikkers LF. Current management of portal hypertension. J Gastrointest Surg. 2005 Sep-Oct;9(7):992-1005. [ $\underline{\text { PubMed }} \mid \underline{\text { DOI }}]$

4. Stiegmann GV. Endoscopic approaches to upper gastrointestinal bleeding. Am Surg. 2006 Feb;72(2):111-5. [PubMed]

5. Lay CS, Tsai YT, Teg CY, Shyu WS, Guo WS, Wu KL, et al. Endoscopic variceal ligation in prophylaxis of first variceal bleeding in cirrhotic patients with high-risk esophageal varices. Hepatology. 1997 Jun;25(6):1346-50. [ $\underline{\text { PubMed | DOI }}$ | Full Text]

6. D'Amico G, Pagliaro L, Bosch J. Pharmacological treatment of portal hypertension: an evidence-based approach. Sem in Liver Dis. 1999;19(4):475-505. [라Med | DOI]

7. Garcia-Tsao G. Current management of the complications of cirrhosis and portal hypertension: variceal hemorrhage, ascites, and spontaneous bacterial peritonitis. Gastroenterology. 2001 Feb;120(3):726-48. [PubMed | Full Text]

8. Dewan KR, Patowary BS, Bhattarai S. A Study of Clinical and Endoscopic Profile of Acute Upper Gastrointestinal Bleeding. Kathmandu University Medical Journal. 2014 Jan-Mar;12(45):21-25. [Full Text]

9. Gurung RB , Joshi G, Gautam N , Pant P , Pokhrel B , Koju R, Bedi TRS. Upper gastro-intestinal bleeding: Aetiology and demographic profile based on endoscopic examination at Dhulikhel Hospital, Kathmandu University Hospital. Kathmandu Univ Med J (KUMJ). 2010Apr-Jun;8(30):208-11. [PubMed]
10. Pagliaro L, D'Amico G, Sörensen TI, Lebrec D, Burroughs AK, Morabito A, et al. Prevention of first bleeding in cirrhosis: a meta analysis of randomized trials of nonsurgical treatment. Ann Intern Med. 1992 Jul 1;117(1):59-70. [PubMed]

11. Sarin SK, Lamba GS, Kumar M, Misra A, Murthy NS. Comparison of endoscopic ligation and propranolol for the primary prevention of variceal bleeding. N Engl J Med. 1999 Apr 1;340(13):988-93. [PubMed | DOI | Full Text]

12. D'Amico G, Pagliaro L, Bosch J. The treatment of portal hypertension: a meta-analytic review. Hepatology. 1995 Jul;22(1):332-54. [PubMed | Full Text]

13. Garcia-Tsao G, Sanyal AJ, Grace ND, Carey W, Practice Guidelines Committee of the American Association for the Study of Liver Diseases; Practice Parameters Committee of the American College of Gastroenterology. Prevention and management of gastroesophageal varices and variceal hemorrhage in cirrhosis. Hepatology. Hepatology. 2007 Sep;46(3):922-38. [PubMed | DOI]

14. Villanueva C, Piqueras M, Aracil C, Gómez C, López-Balaguer JM, Gonzalez B, et al. A randomized controlled trial comparing ligation and sclerotherapy as emergency endoscopic treatment added to somatostatin in acute variceal bleeding. J Hepatol. 2006 Oct;45(4):560-7. Epub 2006 Jun 28. [PubMed | DOI | Full Text]

15. Abraldes JG, Villanueva C, Bañares R, Aracil C, Catalina MV, GarciA, Pagán JC, et al. Hepatic venous pressure gradient and prognosis in patients with acute variceal bleeding treated with pharmacologic and endoscopic therapy. J Hepatol. 2008 Feb;48(2):229-36. [PubMed | DOI | Full Text]

16. Bosch J, Thabut D, Albillos A, Carbonell N, Spicak J, Massard $\mathrm{J}$, et al. Recombinant factor VIIa for variceal bleeding in patients with advanced cirrhosis: a randomized, controlled trial. Hepatology. 2008 May; 47(5):1604-14. [PubMed | DOI]

17. Sarin SK, Wadhawan M, Agarwal SR, Tyagi P, Sharma BC. Endoscopic variceal ligation plus propranolol versus endoscopic variceal ligation alone in primary prophylaxis of variceal bleeding. Am J Gastroenterol. 2005 Apr;100(4):797-804. [PubMed | DOI | Full Text] 
18. Garcia-Tsao G, Sanyal AJ, Grace ND, Carey W. Prevention and management of gastroesophageal varices and variceal hemorrhage in cirrhosis. Hepatology. 2007 Sep; 46(3):922-38. [PubMed | DOI]

19. Santos MM, Tolentino LH, Rodrigues RA, Nakao FS, Rohr MR, de Paulo GA, et al. Endoscopic treatment of oesophageal varices in advanced liver disease patients:band ligation versus cyanoacrylate injection. Eur J Gastroenterol Hepatol. 2011 Jan; 23(1):60-5. [PubMed | DOI]

20. Karsan HA, Morton SC, Shekelle PG, Spiegel BM, Suttorp MJ, Edelstein MA, et al. Combination endoscopic band ligation and sclerotherapy compared with endoscopic band ligation alone for the secondary prophylaxis of esophageal variceal hemorrhage: a meta-analysis. Dig Dis Sci. 2005 Feb; 50(2):399-406. [PubMed]
21. Ding SH, Liu J, Wang JP. Efficacy of beta-adrenergic blocker plus 5-isosorbide mononitrate and endoscopic band ligation for prophylaxis of esophageal variceal rebleeding: A meta-analysis. World J Gastroenterol. 2009 May 7;15(17):2151-5. [릴ed | Full Text]

22. Khan A, Manan F, Din R. Outcome of Endoscopic Band Ligation for Oesophageal Variceal Bleed in patients with Chronic Liver Disease: Gomal Journal of Medical Sciences. 2013 Jan-June;11(1):84-87. [Full Text]

23. Abbasi A, Bhutto AR, Bhatti KI, Mahmood K, Lal K. Outcome of band ligation in oesophageal varices. J Pak Med Assoc. 2013 Aug;63(8):983-987. [Full Text] 